\title{
O teatro na educação brasileira para a construção do pensamento científico: um estudo na formação inicial de professores
}

\section{Drama in Brazilian education for the construction of scientific thinking: a study in pre-service teacher education}

Barbara Doukay Campanini ${ }^{1}$

Marcelo Borges Rocha ${ }^{2}$

\author{
'Universidade Federal do Tocantins (UFT), Campus de Arraias, TO, Brasil. \\ Autor Correspondente: barbara.campanini@uft.edu.br \\ ${ }^{2}$ Centro Federal de Educação Tecnológica Celso Suckow da Fonseca (CEFET), Rio de Janeiro, RJ, Brasil.
}

Resumo: Ao longo da nossa história o teatro tem sido utilizado como estratégia pedagógica para o ensino de ciências. Este recurso didático permite desenvolver o pensamento crítico por meio de uma linguagem poética que potencializa o pensamento científico por intermédio da representação, da observação e do questionamento, possibilitando a organização de ideias para uma formação científica de qualidade. Neste artigo, analisamos a produção e a utilização de dois roteiros para a elaboração dos planos de aula de um grupo de 20 licenciandos do curso de Pedagogia da Universidade Federal do Tocantins, que colaboraram com esta pesquisa. Foram discutidas as contribuições do uso do teatro científico para o ensino, assim como as possibilidades e entraves observados durante todo o processo em que participaram das atividades para a construção deste aparato pedagógico. Com base nos dados apresentados, acreditamos que o teatro seja um recurso com grande potencial de divulgação científica para a formação dos estudantes.

Palavras-chave: Formação inicial do professor; Teatro e educação; Pensamento científico; Sequência didática interativa.

Abstract: Throughout our history, drama has been used as a pedagogical strategy in science teaching. This didactic resource allows for the development of critical thinking through poetic language that enhances scientific thinking through representation, observation and questioning, enabling the organization of ideas for quality scientific training. In this article, we have analyzed the production of two scripts and their use for the preparation of the lesson plans by a group of 20 undergraduate students in the Pedagogy program at Universidade Federal do Tocantins, who collaborated with this research. The contributions of the use of scientific drama to teaching were discussed, as well as the possibilities and obstacles observed throughout the process in which the undergraduates participated in the activities for the construction of this pedagogical apparatus. Based on the data presented, we believe that drama is a resource with great potential for scientific dissemination and for training students.

Keywords: Teacher education; Drama and education; Scientific thinking; Interactive didactic sequence.

Recebido em: 12/05/2020

Aprovado em: 12/09/2021 


\section{Introdução}

A busca pelo domínio da tecnologia tem promovido amplas discussões sobre os impactos gerados ao meio ambiente; e o aspecto social passou a ser tratado com maior notoriedade em relação à aproximação do conhecimento científico e tecnológico com a população. Cunha (2017) enfatiza que esse olhar para a formação científica no Brasil teve início na década de 1930, quando foi incorporado ao currículo escolar. Com isso, almejava-se que as pessoas pudessem compreender essas transformações de forma gradativa, inserindo-as em sua prática social.

No entanto, para o desenvolvimento desta compreensão, entendemos que a apropriação do conhecimento científico possibilita ao sujeito entender a linguagem científica inerente ao funcionamento interno da Ciência. Ao compreender a natureza da ciência, por exemplo, considera-se que ocorra um estreitamento nas lacunas do ensino pautado na educação científica necessária para o desenvolvimento de uma sociedade contemporânea (OSBORNE, 2007).

As transformações que vêm ocorrendo no desenvolvimento científico estão relacionadas com a leitura crítica de um mundo contemporâneo por meio de ações que facilitem o ensino e a aprendizagem. Dessa forma, o papel do professor e a sua formação envolvem a compreensão de que os saberes docentes vinculados à prática docente tornam-se fundamentais neste processo, contribuindo para um ensino diferenciado por meio de ações interativas que permitam a construção do conhecimento de forma individual ou coletiva (CAMPANINI, 2019).

Com isso, a educação científica desejada pode ser encontrada em diversos caminhos, entre eles, na fusão entre ciência, arte, aprendizado e diversão. A “[...] linguagem da arte permite um pensar crítico e reflexivo, na qual o novo possa ser experimentado, deixando de seguir apenas por caminhos já demarcados, onde as possibilidades de se reinventar se tornam infinitas" (CAMPANINI, 2019, p. 26). Os diversos meios interativos de divulgar a ciência vêm ganhando espaço, se tornando um dos maiores canais de informação responsáveis por discutir os avanços científicos e tecnológicos, oportunizando uma formação científica que possibilite ampla familiarização com os conceitos científicos por parte da população, por apresentarem uma linguagem mais acessível a todos (MORTIMER, 2002; ROCHA, 2012).

Segundo Rodrigues (2018), pesquisadores como Robert Root-Bernstein da Michigan State University (MSU) e o professor visitante da Faculdade de Artes e Ciências da Universidade Harvard, João Silveira, corroboram essa discussão, defendendo a ideia de integração da sociedade com o desenvolvimento de habilidades de comunicação que estabeleçam a conexão entre a Ciência, Tecnologia, Engenharia, Artes e Matemática, em um movimento chamado Steam (denominação desta ação em inglês).

O movimento Steam é conhecido como uma metodologia que permite agir de forma interdisciplinar, desenvolvendo habilidades de comunicação, trabalho coletivo e o pensamento criativo no aluno, por meio de recursos lúdicos que se encaixem com facilidade ao currículo escolar auxiliando o processo de ensino e aprendizagem, tornando-o instigante e prazeroso. 
Nesse sentido, para que o canal que se pretende estabelecer entre a ciência, a arte e o público leigo possibilite essa integração é necessário ter o domínio do assunto proposto, habilidade e compreensão do veículo de divulgação que está sendo utilizado para a construção do conhecimento, seja por meio do teatro, revistas, museus, entre outros (BARBOSA; AIRES; GONÇALVES, 2012; CAMPANINI, 2019; ISZLAJI et al., 2014).

Portanto, é possível afirmar que o teatro também atua "[...] como ferramenta pedagógica na sala de aula, com o objetivo de fixar conhecimentos" ou como "[...] teatroeducação com fins socioculturais e artísticos, geralmente oferecido como atividade extracurricular" em espaços socioeducativos (COELHO, 2014, p. 6).

\section{O teatro educativo e a sua relação com o ensino no Brasil}

A relação entre o ensino e o teatro vem sendo desenvolvida ao longo de vários anos. O espetáculo teatral sobreviveu às transformações da sociedade, assim como os avanços científico e tecnológico com a chegada do rádio, da televisão e do cinema. Pelo fato de reunir diversas atividades de entretenimento, os espetáculos teatrais provocam a emoção por contato físico e visual, mediante a representação corporal, a música e o figurino, no qual o real e o imaginário se fundem através de um cenário de luzes, cores e sons que envolvem a todos.

Diante desse contexto, serão apresentadas neste artigo informações relevantes acerca de um dos principais caminhos trilhados pelo teatro brasileiro. Será abordada a evolução do teatro no contexto educativo e suas contribuições na educação em ciências, ou seja, destacando a importância da relação histórica do teatro com o ensino no Brasil.

No entanto, a falta de registros dos materiais produzidos à época em que o teatro chega ao Brasil é vista como uma significativa dificuldade para os historiadores, sendo de grande necessidade esse tipo de levantamento para possíveis contribuições na área teatral (SOUSA, 1960).

Percorrendo a evolução da história do teatro no Brasil, a divisão da história do teatro é marcada por períodos, tendo início no século XVI com a ação dos jesuítas na forma de autos que versam sobre a vida dos santos (SOUSA, 1960). Os registros surgem efetivamente na história brasileira a partir do período da colonização, no qual os jesuítas fizeram uso do teatro para catequizar os povos indígenas, impondo que aprendessem a cultura evangélica. Sousa (1960) revela que, após perceberem as habilidades de representação dos índios, durante as atividades do aldeamento, os jesuítas passaram a explorar o talento desses povos por possuírem natural capacidade para a dança e a destreza com os instrumentos musicais.

As peças teatrais eram produzidas pelos sacerdotes das companhias e representadas geralmente por atores amadores - como indígenas já catequizados, brancos, mamelucos - que atuavam nas festas dos padroeiros ou encerramentos escolares. No século XVI, a celebração em festas de colégio mais conhecida era a das Onze Mil Virgens e a das Congregações de Nossa Senhora, que alcançavam proporções extraordinárias em São Paulo (FARIA, 2012).

O auto de Pregação Universal (1567-1570), de Nóbrega e Anchieta, marcou a fundação do teatro brasileiro, sendo considerado o primeiro escrito no Brasil. Subsequentemente, todas as informações dentro da cronologia do teatro representado a partir de então, é configurada por informações contidas em crônicas que foram encontradas nas correspondências dos jesuítas da Companhia de Jesus no Brasil, 
coordenada pelo padre Serafim Leite (SOUSA, 1960). Faria (2012) destaca que, no século XVII, a história do teatro jesuítico entra em decadência em relação ao teatro catequista. Esse período marca, também, uma época de crise do teatro no Brasil.

Somente a partir do século XVIII o teatro passou a revelar um caráter educativo, tornando-se, mais ou menos, oficial. O ano de 1777 dispôs de um alvará que determina o teatro como estabelecimento de ensino para noções de política, moral, amor à pátria, valor, zelo e fidelidade aos soberanos. Passaram, então, a surgir no século XIX os primeiros edifícios destinados às representações dramáticas, como a Casa da Ópera, ou também a chamada Casa da Comédia. Nessa época, o Brasil já possuía poetas, prosadores e artistas reconhecidos. Porém, somente entre o final do século XVIII e início do século XIX, com o Marquês Lavradio, o Brasil passou a ter proteção do Governo para o desenvolvimento do teatro (SOUSA, 1960).

No entanto, surgiu a censura teatral que teve seu início manifestado em 1824, dispondo do edital expedido pela Polícia da Côrte. Sucessivamente, em 1829, foi exigido que as peças teatrais passassem por análise prévia antes de serem aceitas para a representação no teatro. Em 1845 foram decididas as regras para a censura, estabelecidas pelo Conservatório Dramático Brasileiro. Nesse ano foram censuradas 228 peças.

A partir do século $X X$, diversos registros trazem sinais de renovação teatral (SOUSA, 1960). O Teatro do Brinquedo de Álvaro Moreira (teve início em 1927) trouxe uma proposta de teatro com reticências, ou seja, o teatro que faz rir e também pensar, mas que teve seu fim em 1937, permanecendo apenas a ação de Os comediantes, em 1938. O teatro do brinquedo não era voltado para crianças, mas possuíam bonecos e caixas que davam a sensação de realidade (SOUSA, 1960).

Em 1938, houve a revolução cênica, representada pelo modernismo e consolidada na ação de Os comediantes de Dulcina de Morais, Pascoal Carlos Magno e Ziembinski, que passou a garantir o desenvolvimento do amadorismo teatral (SOUSA, 1960).

Em 1944 foi quando o teatro realmente direcionou-se para o público infantil. Pascoal Carlos Magno projetava a base para o teatro infantil, mas com a ação de adultos. Nos períodos anteriores a este não se pensava no teatro com o olhar para crianças, apenas se fazia teatro com crianças, para o público adulto. Os escritores passaram então a ter a preocupação com a adequação do texto, assim como com o elenco e com a montagem das peças destinadas às crianças. Nomes famosos como Maria Clara Machado e Modesto de Abreu fizeram parte dessa história (FARIA, 2012; SOUSA, 1960).

Tratando-se de um fenômeno atual, o teatro alcança diversas vertentes como "[...] o currículo da escola formal, a temática da preparação de professores, os cursos de iniciação e as práticas metodológicas disseminadas nas escolas e centros culturais, as formas de capacitação voltadas para as carreiras profissionais" (FARIA, 2013, p. 447), entre outros. Dessa forma, a presença do teatro voltado para a Educação tem seu início bem recente em nossa história. Com isso, os registros históricos também passaram a ser datados com maior eficácia, desde então. 
Nesse sentido, a temática do uso do teatro direcionado ao ensino nos permite, por meio do resgate histórico e cultural no Brasil, investigar as contribuições desta ferramenta didática relativa à ação pedagógica, procurando evidenciar os estudos mais relevantes e as metodologias utilizadas no que se refere ao ensino de ciências.

A partir do comando de D. João VI, gradativamente, as escolas de teatro (como as escolas de artes e ofício) foram ganhando maior espaço no que se refere a "projetos artísticos associados a iniciativas pedagógicas informais" (FARIA, 2013), muito conhecidas como o Grupo de Teatro Experimental e Grupo Universitário de Teatro (administrado por Alfredo Mesquita e Décio de Almeida Prado), que influenciaram a origem da Escola de Arte Dramática aliada à Escola de Comunicações e Artes da Universidade de São Paulo, o Tablado representado por Maria Clara Machado, no Rio de Janeiro, a Fundação Brasileira de Teatro (presente na Faculdade de Arte em Brasília, DF) representada por Dulcina de Moraes, entre tantas outras que continuam operantes nos dias atuais, em sua proposta original ou fundidas em parcerias com outras instituições.

Foi a partir do marco da Escola Nova, que emergiu em meados da década de 1930, que Augusto Rodrigues criou a Escolinha de Arte do Brasil, localizada no Rio de Janeiro, que se expandiu para outras localidades no país, resultando em um dos centros de referência na formação de professores. Posteriormente, na década de 1960, o teatro pautou-se também nas práticas pedagógicas com base nas Leis de Diretrizes e Bases da Educação ( $n^{\circ}$ 4024/1961) que já encorajava essa prática para o ensino e na formação de professores (BRASIL, 1961).

Entre os anos 1970 e 1980, o teatro surgiu na educação básica como forma de arte na disciplina de educação artística. No entanto, essa prática reunia a responsabilidade em formar os alunos em muitas linguagens da arte e, com isso, não foi bem estruturada. O governo reconheceu a inviabilidade dessa prática, porém, objetivou o ensino de artes em 'artes plásticas, música, teatro e dança', sem que esses saberes fossem realmente aprofundados. Contudo, a arte precisava ser melhor estruturada. Foi a partir dessa crise relacionada à formação do professor que se originou a evolução das artes com habilitações opcionais para "Música, Artes Plásticas, Desenho ou Artes Cênicas", sendo que esta última envolvia a transformação do "Teatro e da Dança, Expressão Corporal e Vocal, Encenação, Cenografia, Técnicas de Teatro e Dança" (FARIA, 2013, p. 450).

Diante dessa perspectiva, iniciou-se a preocupação e o incentivo relativo à pesquisa nessa área. Muitas instituições superiores passaram a oferecer cursos de Cinema, Música, Dança, Artes Visuais, Teatro, entre outros, sendo uma boa parte voltada para a formação de professores, consolidando o Bacharelado e a Licenciatura para o teatro. Com isso, houve um crescimento qualitativo no decorrer dos anos e, da década de 1990 para os dias atuais, ocorreram grandes mudanças relativas às metodologias utilizadas no ensino de artes cênicas devido aos estudos realizados em relação à sua história, o domínio da linguagem teatral e o intercâmbio de informações estruturadas dentro e fora do Brasil (FARIA, 2013).

A arte hoje não está restrita ao território brasileiro, ela percorre diversos caminhos em evidência com o mundo todo, fala diversas línguas, abraça vários gêneros e aproxima a informação a todo tipo de público. Portanto, podemos afirmar que a situação do teatro brasileiro mudou ao longo dos anos e as sua contribuição em 
relação ao ensino tem sido consolidada por meio da estruturação de novas metodologias, desde a educação básica ao ensino superior. O teatro no ensino passou a ser discutido com base em referenciais de diferentes ramos da educação, em pesquisas de programas de mestrado e doutorado pelo Brasil (FARIA, 2013).

\section{A importância do teatro no Ensino de Ciências através das práticas educativas}

As experiências adquiridas ao longo da história da humanidade permitiram a construção de uma sociedade que possui diferentes culturas que sofrem constante influência dos avanços científicos e tecnológicos. Essa questão está ligada a uma formação que envolve os diversos saberes de diferentes culturas, relacionando-os aos saberes experienciais e disciplinares vinculados ao ensino tradicional e à redefinição das ações pedagógicas contemporâneas. Essa relação complexa nos leva a pensar sobre o saber que é formado por diferentes saberes inerentes a diversas fontes. Esse conhecimento envolve os saberes experienciais, profissionais, didáticos e curriculares.

Com isso, a constante atuação docente ligada à elaboração de um novo formato de estratégias de ensino, com a utilização de novas metodologias, como o desenvolvimento de um livro, um documentário ou uma peça de teatro, entre outros recursos, também são instrumentos que podem ser utilizados no processo de ensino e aprendizagem, que possuem grande relevância em relação à demanda de interesses e adequações do modelo de educação atual (CAMPANINI, 2019).

O modo de se pensar o ato de educar precisa refletir a necessidade de uma educação tecnológica que proporcione a possibilidade de mudanças nas propostas pedagógicas, onde o ensino tradicional dê lugar à interatividade. Contudo, essa inovação também nos remete à complexidade da prática educativa, que requer a transformação do olhar pedagógico, atuando com clareza quanto ao posicionamento do educador diante de tais desafios.

A utilização de recursos como o teatro tem se tornado uma atividade que auxilia na aproximação do aluno com o objeto de estudo, facilitando o processo de ensino e aprendizagem. Nesse sentido, Pereira e Santos (2017, p. 131-132), que trabalham com o teatro na formação de professores, discutem sobre a divulgação da ciência por meio desse canal interativo de informações, que proporciona "[...] um ambiente propício aos alunos da educação básica a se interessarem pela ciência". Para isso, é indispensável estabelecer a conexão entre o ensino e a inovação tecnológica, para que se torne possível organizar uma aproximação entre o aluno e a escola, possibilitando maior integração e apropriação do educando para um processo de formação mais eficiente.

As transformações em que a tecnologia vem direcionando o ritmo de vida da sociedade marcam a imprescindibilidade de uma educação contemporânea que atua diretamente na integração dos avanços científicos e tecnológicos ao contexto escolar. Silva et al. (2018) abordam essa questão, refletindo sobre as necessidades para o desenvolvimento de habilidades voltadas para os dias atuais, em vista do uso de novas ferramentas didáticas que abarquem o "currículo, ensino, aprendizagem e avaliação".

Amparando essas práticas, existe a possibilidade de criar sequências de atividades que possam ser inseridas na construção de um produto final, como citado anteriormente, seja um documentário, um guia didático, um roteiro para peça teatral, 
entre outros. Essa sequência de atividades pode gerar ações interativas e investigativas que, quando bem estruturadas, facilitam a atuação do professor na mediação da construção do conhecimento (OLIVEIRA, 2013).

Desse modo, destaca-se a importância da responsabilidade de atuação dos professores em relação aos saberes docentes adquiridos por meio da profissionalização e da experiência em sala de aula, recorrendo a práticas que possibilitem desenvolver o pensamento crítico do aluno, atendendo às necessidades dos novos modelos sociais. Diante deste cenário, o papel da universidade, enquanto instituição, também precisa ser analisado "[...] visto que a ação de docentes e discentes não se dá num universo à parte da realidade social no qual se insere. A própria definição de seu projeto políticopedagógico institucional estará diretamente relacionada a esses fatores determinantes" (PIMENTA; ANASTASIOU, 2014, p. 167).

Assim sendo, a universidade assume, por meio de seu papel social e de suas ações pedagógicas, a responsabilidade de formar profissionais que atendam as necessidades institucionais, políticas e sociais no que se refere à elaboração, desenvolvimento e transposição do conhecimento. No entanto, ainda é possível observar uma significativa contradição em relação ao que se é discutido em termos de práticas pedagógicas e às ações realizadas dentro das universidades, nas quais o ensino permanece sendo desenvolvido nas disciplinas ministradas na graduação por um:

[...] modelo metodológico tradicional [...] predominantemente expositivo por parte do professor e passivo por parte do aluno, fundado basicamente em memorização, e das próprias relações individualistas, competitivas e de não comunicação entre docentes e-em decorrência - entre disciplinas curriculares, assim como entre os alunos (PIMENTA; ANASTASIOU, 2014, p. 170-171).

Portanto, com o intuito de provocar reflexões e mudanças no modo de se pensar o processo de ensino e aprendizagem na formação de professores, foi elaborada uma sequência didática interativa (SDI), aplicada a licenciandos do curso de Pedagogia, com o intuito de propor um olhar imerso na importância do papel do professor no planejamento e realização das atividades de sala de aula. Assim, com estes dados buscamos investigar as contribuições de práticas do teatro científico na formação de futuros professores da educação básica.

\section{Percurso metodológico}

As estratégias de ensino possuem papel relevante na transposição didática, onde ocorre a transmissão de informações, em que o foco se encontra na aproximação do conteúdo escolar com a vivência do estudante de uma forma contextualizada e significativa, desenvolvendo sua capacidade crítica e reflexiva.

Oliveira (2013) descreve como didática a definição de Luiz Carlos Pais (PAIS, 2001, p. 11 apud OLIVEIRA, 2013, p. 19) citada em seu livro como "[...] elaboração de conceitos e teorias que sejam compatíveis com a especificidade educacional do saber escolar [...] tanto no nível experimental da prática pedagógica, como no território da pesquisa acadêmica".

No entanto, a falta de preparo ou conhecimento na formação torna-se um fator limitante para o uso de recursos didáticos diferenciados para o ensino nas escolas. Um dos maiores desafios dessa prática está pautado na dificuldade em aliar teoria e 
prática, tendo em vista que os benefícios se traduzem no desenvolvimento de habilidades de comunicação e interação por meio da aprendizagem.

Com base nesse entendimento, Oliveira (2013, p. 43) elaborou uma SDI direcionada para o processo de formação de professores. Para o autor "[...] o conhecimento é produção científica e o saber está ligado com a intuição e com a realidade sensível" no qual "procuramos aprofundar nossas pesquisas".

Assim sendo, optamos por desenvolver uma SDI para trabalhar o planejamento e a pesquisa dentro de uma proposta pedagógica que permitisse ao licenciando vivenciar o papel de aluno e professor durante a sua formação. Por se tratar de uma metodologia de ensino que envolve ações que estão diretamente ligadas à prática docente "[...] que vai desde o domínio dos conteúdos específicos com o qual se trabalha a utilização de métodos e técnicas, até a produção de um novo conhecimento e saber" que contribuam para "[...] os aspectos técnicos, pedagógicos e científicos, que orientam a prática docente" (OLIVEIRA, 2013, p. 51), acreditamos ser uma experiência com significativas contribuições.

Pensando nisso, o presente artigo corresponde ao recorte de uma pesquisa de doutorado, na qual utilizamos parte de uma SDI para essa discussão. O desenvolvimento do roteiro didático e a elaboração do plano de aula, com base no roteiro elaborado pelos licenciandos, fazem parte de uma das etapas que será discutida a seguir.

Para a confecção dos roteiros e planos de aula, os licenciandos, que participaram voluntariamente da pesquisa, foram orientados a trabalhar de forma individual e/ou coletiva (formando grupos de até cinco alunos). Durante todo o processo de produção foram realizados oito encontros com duração de 50 minutos cada. Esses encontros foram compostos por uma SDI constituída por atividades como rodas de conversa, questionário pré e pós atividades, elaboração de conceitos prévios para discussões em pequenos e grandes grupos, leitura de textos e roteiros adaptados para o ensino de ciências, utilização do laboratório de informática para auxiliar a busca de informações complementares, além do uso de vídeos e documentários e dicas para elaboração dos roteiros e planos de aula.

Os participantes deste estudo foram no total 20 licenciandos do $5^{\circ}$ período, sendo 14 do gênero feminino e seis do gênero masculino, com idades entre 18 e 33 anos - do curso matutino de Pedagogia da Universidade Federal do Tocantins (UFT). Os participantes autorizaram a divulgação dos dados por meio do termo de consentimento livre e esclarecido e a pesquisa foi submetida ao Comitê de Ética e Pesquisa (CEP) - seguindo as normas da Resolução da CNS/MS n¹96/96 - número 3.510.550.

Para que fosse possível analisar todo o processo de forma qualitativa, os dados coletados, na parte da SDI apresentada neste estudo, foram registrados por meio de fotos, diário de bordo (no qual foram feitas descrições minuciosas de cada momento das atividades) e a entrega de rascunhos utilizados para elaboração das atividades, assim como os roteiros e planos de aula.

Com base na descrição dos dados acima, esta pesquisa se caracteriza como um estudo de caso que consiste em explorar situações e os limites da vida real - sendo um método de abordagem de investigação que visa entender como ou porque um determinado evento acontece - muito utilizado para se estudar aspectos sociais de forma exploratória, explicativa e descritiva (GIL, 2002). 
Os dados foram analisados à luz da Análise de Conteúdo, sendo o método considerado o mais adequado para essa pesquisa por se tratar de um conjunto de técnicas de análise que envolve determinados procedimentos, sistemáticos e objetivos de descrição do conteúdo e dos indicadores das mensagens (BARDIN, 2016). Desse modo, a Análise de Conteúdo tem como base a criação de categorias que consistem em agrupamentos que estejam previamente estabelecidos de forma expressiva. Por conseguinte, a categorização dos dados foi realizada em duas etapas: isolamento/ agrupamento dos elementos encontrados e a classificação desses elementos de acordo com a organização das mensagens obtidas e suas variáveis (BARDIN, 2016).

A partir destes pressupostos, foram criadas categorias e subcategorias representadas da seguinte forma:

- Categoria 1: Roteiro didático. Subcategorias: (1) Análise do conteúdo didático e Características; (2) Os principais aspectos do diálogo dos personagens, com base nos temas Plantas e suas funções (I), A festa dos invertebrados (II), Os cinco sentidos do corpo humano (III) e A família dos órgãos (IV).

- Categoria 2: Planejamento da aula a partir do roteiro didático. Subcategorias: (1) escolha do público alvo; (2) conteúdo didático aplicado; (3) objetivo a ser alcançado; (4) metodologia utilizada; (5) recursos didáticos utilizados; (6) formas de avaliação; (7) tempo previsto para a realização da atividade.

- Categoria 3: Avaliação e expectativas. Subcategorias: (1) Relação do Ensino de Ciências com o Teatro Científico (TC); (2) Relação dos pontos positivos e negativos quanto às atividades do TC após a SDI - para que fosse possível analisar de que forma os licenciandos percebiam o ensino de ciências através do teatro, após terem participado das atividades da SDI e como elencavam os contrapontos deste recurso para o ensino.

Vale destacar que a criação das subcategorias contribui para uma discussão mais detalhada dos resultados encontrados ao longo da coleta de dados. E, ainda, nos fornece subsídios para problematizar as percepções dos estudantes envolvidos na pesquisa.

\section{Resultados e discussões}

\section{Elaboração do roteiro didático}

Após terem passado por algumas etapas iniciais inerentes à SDI - de elaboração de conceitos prévios para realização das discussões e rodas de conversa, os licenciandos deram continuidade às atividades propostas, pesquisando sobre os conteúdos didáticos voltados para o ensino de ciências nos anos iniciais -, sendo orientados, também, para o desenvolvimento do roteiro. A escolha dos temas se deu a partir do trabalho realizado coletivamente, em que todos os licenciandos trocaram informações, experiências e saberes durante a fase de pesquisa. Dos quatro temas abordados na categoria 1 foram selecionados para este artigo apenas dois roteiros: Plantas e suas funções (I) e A festa dos vertebrados (II) para serem discutidos a seguir.

Para a análise dos roteiros foram criadas subcategorias que nos permitiram verificar as características dos personagens e a relação estabelecida com a biologia, identificando os principais aspectos encontrados na fala dos personagens que se 
encaixassem na abordagem didática relacionada ao conteúdo proposto. Por ser tratar de assuntos diferentes, as subcategorias permitiram padronizar alguns aspectos didáticos necessários para esta análise.

No roteiro Plantas e suas funções, a peça teatral ocorre em um viveiro de plantas, onde as funções das plantas dialogam entre si para descobrir qual é a mais importante. "O intuito de se trabalhar com as funções das plantas é mostrar para os alunos que elas são a base para a manutenção da vida", relatam os licenciandos. A peça retrata uma conversa entre as partes de uma planta, na qual cada uma afirma que a sua função é sempre mais importante que a de outra. No quadro 1 e no quadro 2 podemos observar essas questões nas narrativas a seguir:

Quadro 1 - Roteiro I Plantas e suas funções - Características e principais aspectos do diálogo do personagens

\begin{tabular}{|l|l|l|}
\hline Personagens & Características & \multicolumn{1}{|c|}{ Principais aspectos da fala dos personagens } \\
\hline Folha & Estressada & Ai, que sol quente... muito calor. \\
\hline Raiz & Mal humorada & $\begin{array}{l}\text { Está reclamando do quê? É porque não é você que está aqui embaixo com } \\
\text { toda essa terra por cima! }\end{array}$ \\
\hline Flores & Esperançosa & $\begin{array}{l}\text { Enquanto vocês reclamam eu fico pensando na beleza dos olhos humanos } \\
\text { quando me virem aqui. }\end{array}$ \\
\hline Caule & Baixa autoestima & $\begin{array}{l}\text { Eeu fico com a parte pesada de sustentar vocês... } \\
\text { Fessoal, parem de reclamar! O importante é que todos nós temos uma função } \\
\text { que auxilia na manutenção da vida na terra. }\end{array}$ \\
\hline
\end{tabular}

Fonte: elaborado pelos autores.

O roteiro retrata de forma descontraída uma polêmica entre as partes de uma planta em que elas discutem algumas de suas funções. O texto trabalha, também, as questões de amizade, tolerância e otimismo por meio das características de cada personagem. A ludicidade com que a peça é tratada permite trazer essas questões de forma humanizada, refletindo-se também no cuidado que precisamos ter uns com os outros e com os seres vivos que nos cercam.

Quadro 2 - Roteiro I Plantas e suas funções - Análise do conteúdo didático

\begin{tabular}{|l|l|}
\hline Personagens & \multicolumn{1}{c|}{ Considerações dos personagens em relação às suas funções } \\
\hline Raiz & $\begin{array}{l}\text { Verdade. Mas sou a mais importante nesse processo porque eu fixo vocês aqui no solo e retiro da } \\
\text { terra os nutrientes que encontro por aqui. }\end{array}$ \\
\hline Folha & Não mesmo senhora Raiz, e o que seria de vocês se eu não fizesse fotossíntese? \\
\hline Flores & $\begin{array}{l}\text { Nós contribuímos de forma única dentro de nossas funções e devemos cumprir com o nosso papel } \\
\text { para termos um ambiente harmonizado, com ar puro...e isso é responsabilidade de todos. }\end{array}$ \\
\hline Caule & $\begin{array}{l}\text { Então todos nós somos importantes na manutenção da vida? Até eu? } \\
\text { Sim. Por isso temos que trabalhar em equipe, ajudando uns aos outros. Eu, por exemplo, garanto a } \\
\text { continuidade da nossa espécie protegendo as sementes das árvores frutíferas. Mas eu não chegaria } \\
\text { nem a existir se não fosse com a ajuda de todos vocês. }\end{array}$ \\
\hline Frutos & \multicolumn{1}{|c|}{ cotonte: elaborado peelos autores. } \\
\hline
\end{tabular}


Ao analisar as falas dos personagens percebe-se que o roteiro trabalha as funções das plantas de forma simples, abordando de forma superficial a fixação no solo, fotossíntese, sustentação e proteção das sementes. Considerando este material como apoio para o conteúdo didático para a prática a ser realizada na escola, as informações contidas no texto proporcionam ao professor ampliar a discussão em outras atividades.

No roteiro A Festa dos Vertebrados, a história se passa na floresta, discutindo-se no texto uma comemoração entre a bicharada, onde só seriam convidados os animais vertebrados. A peça expõe as diferenças entre os animais vertebrados e invertebrados e suas adaptações na floresta. Podemos identificar tais características nas falas dos personagens a seguir, no quadro 3 e no quadro 4:

Quadro 3 - Roteiro II A festa dos Vertebrados - Características e principais aspectos do diálogo dos personagens

\begin{tabular}{|l|l|l|}
\hline Personagens & \multicolumn{1}{|c|}{ Características } & \multicolumn{1}{|c|}{ Principais aspectos da fala dos personagens } \\
\hline Minhoca & $\begin{array}{l}\text { Defensores dos direitos } \\
\text { dos animais }\end{array}$ & $\begin{array}{l}\text { Ei, eu quero entrar na festa. A floresta é de todos e nós também temos esse } \\
\text { direito. }\end{array}$ \\
\hline Caracol & $\begin{array}{l}\text { Defensores dos direitos } \\
\text { dos animais }\end{array}$ & $\begin{array}{l}\text { Senhor Lobo, por qual motivo não podemos entrar? } \\
\text { Lobo }\end{array}$ \\
Segurança da festa & $\begin{array}{l}\text { A festa é somente para animais vertebrados e vocês não possuem coluna } \\
\text { vertebral. }\end{array}$ \\
\hline Cachorro & Convidado & $\begin{array}{l}\text { O mínimo que posso dizer a vocês é que precisariam ter medula espinhal e } \\
\text { coluna vertebral. Por isso somos os seres vivos mais evoluídos do planeta. }\end{array}$ \\
\hline Leão & Dono da festa & $\begin{array}{l}\text { Ei, pessoal...relaxa. Podem entrar sim, mas cuidado. Os mais adaptados } \\
\text { sobrevivem por aqui...e o menos adaptados, bem, esses viram comida. Hahaha. }\end{array}$ \\
\hline
\end{tabular}

Fonte: elaborado pelos autores.

O roteiro aborda as principais características dos vertebrados, mas não aprofunda a razão pela qual existe essa diferença e porque ela daria mais possibilidades de locomoção e sustentação a esses animais do que aos outros que foram impedidos de entrar na festa. No entanto, há a possibilidade de levantar essas questões em uma SDI sobre a evolução das espécies, adaptação, diferença entre animais vertebrados e invertebrados, classificação dos animais e cadeia alimentar. Contudo, o texto destaca, nas características dos personagens, a questão da igualdade dos direitos, a exclusão e a indiferença. A abordagem dessas questões é de grande relevância, pois envolve assuntos polêmicos vivenciados constantemente pela sociedade, como o preconceito e a intolerância.

Quadro 4 - Roteiro II A festa dos Vertebrados - Análise do conteúdo didático

\begin{tabular}{|l|l|}
\hline Personagens & \multicolumn{1}{c|}{ Considerações dos personagens em relação às suas funções } \\
\hline Minhoca & $\begin{array}{l}\text { Mas para sua informação eu ajudo na recuperação do solo. Me alimento de animais e plantas em } \\
\text { decomposição. Não sirvo só para virar alimento de passarinho. }\end{array}$ \\
\hline Caracol & $\begin{array}{l}\text { Por mim tudo bem, eu me viro aqui dentro da minha concha. Os predadores não me percebem por } \\
\text { causa da minha cor que se camufla com a terra. }\end{array}$ \\
\hline Lobo & $\begin{array}{l}\text { Eca! Sua composição é nojenta. Vocês tem o corpo muito mole. Mas ok, na pior vão virar comida de } \\
\text { tartarugas, cobras, sapos e pássaros. }\end{array}$ \\
\hline Cachorro & $\begin{array}{l}\text { Prefiro não me misturar. Vou procurar bichos mais interessantes que possuam um corpo bem estruturado, } \\
\text { cérebro, músculos e esqueleto como eu. }\end{array}$ \\
\hline Leão & $\begin{array}{l}\text { Ah, Cachorro. Vê se vai roer um osso. Na verdade você não anda pegando ninguém. E vê se fica esperto } \\
\text { com as gatinhas porque quem manda nesse reino aqui sou eu. Arrrrrrr. }\end{array}$ \\
\hline
\end{tabular}


Na fala dos personagens são mencionadas, de maneira divertida, questões sobre decomposição, presa e predador e a estrutura básica dos animais. Essa abordagem auxilia a elaboração de propostas de atividades que permitam aos alunos trocarem informações acerca do tema, relacionando-as com suas próprias experiências.

Com isso, ao utilizar uma peça teatral estruturada e planejada de acordo com a necessidade do público que se pretende atingir, esta ação possibilita a compreensão acerca do tema estudado na sala de aula. Embora o texto não retrate de forma ampla todos os aspectos do conteúdo didático, as atividades programadas na SDI auxiliam na complementação desse processo. Souza et al. (2015) relatam a experiência de um trabalho desenvolvido com licenciandos em Química, em que os autores enfatizam a necessidade de se ter uma postura ativa e produtiva no desenvolvimento da prática pedagógica na qual "[...] o grupo assume um papel de articulador no processo de ensino-aprendizagem" (SOUZA et al., 2015, p. 5), tornando o processo de ensino e aprendizagem favorável à construção do conhecimento, compartilhando os saberes adquiridos, de acordo com cada cultura no âmbito familiar.

Em vista disso, o intuito da SDI tem como propósito desenvolver o conhecimento de forma individual e coletiva, na qual os alunos trocam informações e experiências formando uma malha de saberes elaborados de forma coletiva (OLIVEIRA, 2013), possibilitando a construção de ideias e conceitos mais significativos para o ensino de ciências. Com isso, o teatro científico funciona como um recurso fundamental para este processo tanto na formação de professores, quanto na sua aplicação em sala de aula.

Sendo assim, consideramos que o recorte da análise discutida neste artigo foram de grande relevância para este processo da SDI. As falhas observadas nos roteiros também foram verificadas e debatidas como contribuições para possíveis complementações didáticas. Dessa forma, essa atividade possibilitou aos licenciandos perceber as perspectivas do teatro para o ensino de ciências e a importância da pesquisa e planejamento para elaboração das aulas, seja qual for o recurso didático utilizado. Esse entendimento se torna possível quando ocorre a experiência com o objeto estudado, proporcionando um ensino e uma aprendizagem prazerosa e efetiva.

\section{Planejando a aula a partir do roteiro}

No fechamento das atividades, os licenciandos elaboraram um plano de aula com base nos roteiros apresentados. Na categoria 2, 'planejamento', pretendeu-se verificar de que forma a experiência que tiveram com a SDI - a partir do uso do teatro científico - poderia contribuir para uma mudança do ponto de vista no planejamento das aulas. Pedimos aos licenciandos que caracterizassem o plano de aula com as seguintes informações: (a) público alvo; (b) conteúdo didático ministrado; (c) objetivo a ser atingido; (d) desenvolvimento da metodologia; (e) recursos utilizados; (f) avaliação; (g) tempo previsto para realização da atividade. O quadro 5 e o quadro 6 foram analisados de acordo com os critérios estabelecidos para a elaboração do plano de aula. 
Quadro 5 - Elaboração do plano de aula I

\begin{tabular}{|c|c|}
\hline \multicolumn{2}{|r|}{ Plano de aula I } \\
\hline Público Alvo & $5^{\circ}$ ano do Ensino Fundamental \\
\hline Conteúdo didático & Funções das plantas \\
\hline Objetivo & $\begin{array}{l}\text { Compreender a importância de se conhecer as principais partes das plantas e as suas funções para a } \\
\text { manutenção da vida. }\end{array}$ \\
\hline Desenvolvimento & $\begin{array}{l}\text { (a) Aula expositiva sobre o conteúdo didático; (b) Elaboração de cartazes informativos de como e porque } \\
\text { preservar as plantas; (c) Montagem e apresentação da peça teatral a partir do roteiro Plantas e suas funções; } \\
\text { (d) Roda de conversa. }\end{array}$ \\
\hline Recursos didáticos & $\begin{array}{l}\text { Computador, data show, cartolina, lápis de cor, canetinha, durex, recortes de revistas e jornais, materiais } \\
\text { para o cenário e figurino. }\end{array}$ \\
\hline Avaliação & Participação dos alunos na roda de conversa. \\
\hline Duração & 4 aulas (as aulas são contadas por dias letivos). \\
\hline
\end{tabular}

Fonte: elaborado pelos autores.

O plano de aula I aponta o $5^{\circ}$ ano do Ensino Fundamental como público alvo, com um total de quatro aulas-dia para aula expositiva e confecção de cartazes na primeira aula, preparação do roteiro, figurino (simples) e ensaio da peça na segunda e terceira aula, apresentação e a roda de conversa na quarta aula.

É possível identificar, na elaboração do plano de aula, que os licenciandos compreenderam, de forma satisfatória, a proposta da SDI, mesmo ainda sendo percebidos alguns pontos engessados, relacionados ao ensino tradicional, como o uso de cartazes, maquetes, entre outros recursos, durante a elaboração das propostas para o desenvolvimento das atividades. A fala dos estudantes em relação a essa ação demonstra o receio em fugir de atividades já conhecidas e que fazem parte do cotidiano das escolas.

No entanto, a montagem e a apresentação da peça nos traz a ideia de que o roteiro anteriormente apresentado possa ser reelaborado com as crianças. Com isso, a participação coletiva para a reestruturação das falas dos personagens permite ampliar as informações que serão apresentadas no roteiro. Isso torna a roda de conversa uma atividade bem interessante do ponto de vista avaliativo.

A participação ativa dos alunos em todas as etapas dessa construção irá possibilitar ao professor identificar as percepções dos educandos em relação à proposta desenvolvida na aula e quais os pontos que precisam ser mais discutidos. De acordo com Oliveira (2013), a SDI auxilia consideravelmente no processo de ensino e aprendizagem, pois permite nivelar o conhecimento entre os alunos por meio da troca de informações.

\begin{tabular}{|c|c|}
\hline \multicolumn{2}{|r|}{ Plano de aula II } \\
\hline Público Alvo & - (educação básica) \\
\hline Conteúdo didático & Animais vertebrados e invertebrados \\
\hline Objetivo & Compreender a formação do corpo dos animais, sua classificação e função no meio ambiente. \\
\hline Desenvolvimento & $\begin{array}{l}\text { (a) Aula expositiva e dialogada acerca do tema exposto; (b) Elaboração coletiva de um jogo didático com } \\
\text { as regras como o Imagem e Ação (com base em pesquisas e discussões durante a aula); (c) Montagem } \\
\text { coletiva e apresentação da peça teatral com base no roteiro reelaborado pelos alunos. }\end{array}$ \\
\hline Recursos didáticos & Computador, data Show, cartolina, papel A4, canetinha, tesoura e materiais para o cenário e o figurino. \\
\hline Avaliação & Questionário \\
\hline Duração & 5 aulas - *as aulas são contadas por dias letivos. \\
\hline
\end{tabular}

Fonte: elaborado pelos autores. 
O segundo plano de aula analisado utilizou como base o roteiro que aborda a estrutura dos animais vertebrados e invertebrados. O objetivo proposto consiste na compreensão das diferenças entre esses animais e o papel que representam em relação ao meio ambiente. O período definido para a realização das ações é de uma semana, sendo uma aula expositiva sobre o tema proposto, uma aula para elaboração e execução do jogo e três aulas para montagem, ensaio, apresentação da peça e a aplicação do questionário. No entanto, os licenciandos não definiram o público alvo e isso dificultou a análise em relação à adequação da linguagem utilizada no roteiro.

A proposta inicial do plano de aula é bem interessante, pois os alunos precisam desenvolver um jogo que envolva as informações debatidas na aula e a pesquisa como trabalho de casa para elaborar as cartas (já pré montadas) e o uso da imaginação para representar essas ideias durante a brincadeira. As informações discutidas para a elaboração do jogo seriam utilizadas para a composição da peça, porém, não ficou clara a ligação estabelecida entre a apresentação do teatro e a forma de avaliação.

O ponto chave da SDI é realizar atividades que sejam interativas, ou seja, a estruturação da ação precisa estar encaixada de modo que permita estabelecer uma sequência didática significativa para o aluno. O conhecimento é produzido por meio da experiência ativa do estudante, o que torna necessário ao professor repensar o ensino e a forma de ensinar, considerando as relações existentes entre os saberes adquiridos ao longo sua formação e experiência profissional para a elaboração de propostas que atinjam adequadamente os objetivos propostos (TARDIF, 2014).

A estruturação dos saberes tem como base a trama de fios que formam uma teia, na qual se estabelece a troca de informações necessárias para a construção do conhecimento coletivo (OLIVEIRA, 2013).

Nesse sentido, afirmamos que, apesar dos contrapontos identificados no desenvolvimento das atividades ofertadas para os licenciandos do curso de pedagogia, todos os participantes foram capazes de avançar em seus conceitos e pré-conceitos em relação ao planejamento das atividades com a proposta do teatro científico, proporcionando momentos que estimulassem a participação ativa diante da construção dos saberes inerentes à sua formação.

\section{Possibilidades e entraves encontrados na utilização do teatro científico na educação}

A Categoria 3 Avaliação e expectativas revela alguns aspectos observados na percepção dos licenciandos entre o Ensino de Ciências e o Teatro Científico, pontuando algumas dificuldades e soluções encontradas nas atividades do TC após a SDI.

Analisando a elaboração dos roteiros, podemos perceber que a necessidade de leitura para elaboração de ideias relativas ao conteúdo desenvolvido na SDI é evidente, pois falta mais propriedade para argumentação nas discussões propostas. Os licenciandos perceberam essa dificuldade logo no início da atividade. Os estudantes que mais se destacaram mencionaram já participar de projetos e ações nas escolas em projetos da universidade.

Durante as atividades foi possível observar a dispersão de alguns licenciandos pela influência de fatores externos - como conversas paralelas nas redes sociais e atrasos, entre outros fatores, que impossibilitaram a organização de ideias de forma mais objetiva - que nos remetem a um aspecto social e cultural em um cenário 
real da sociedade que o mundo moderno nos proporciona. No entanto, é possível pensar em estratégias que auxiliem o professor a minimizar tais interferências.

Nesse sentido, as soluções necessárias para esse contexto consistem em aprimorar o preparo de atividades que envolvam mais ações diferenciadas, tornando a prática de atividades interativas uma rotina no dia a dia dos estudantes. Embora seja muito discutido o uso de atividades lúdicas que envolvam ciência e arte, o uso de tais recursos quase não são realizados, tanto nas escolas para alunos da educação básica quanto para a formação de professores. Silveira, Silva e Ribeiro Filho (2009) corroboram esta questão enfatizando que a articulação entre a ciência e a arte aproxima o desenvolvimento científico das pessoas, ilustrando as mudanças que ocorrem ao longo dos anos e, assim, espera-se que o indivíduo reflita sobre os fatos e amplie o interesse e o olhar sobre os acontecimentos que impactam e influenciam a sociedade.

Assim sendo, a ideia defendida nesta e em outras pesquisas - preocupadas com a formação dos nossos futuros professores, que amanhã estarão alfabetizando crianças e preparando-as para serem adultos críticos e formadores de opiniões - é que o ensino envolve algumas questões complexas e abstratas que poderiam ser superadas quando vivenciadas em nosso cotidiano. Acreditamos que a proposta de atividades relacionadas ao uso do teatro científico possa ter contribuído para a formação dos licenciandos. E ainda, ter provocado a reflexão sobre a importância do planejamento de uma SDI, de modo que contribua para a construção do conhecimento de forma coletiva, divertida e colaborativa. Reforçando assim, a importância em acreditar que o saber não caminha em uma única direção, sendo possível compreender todas as possibilidades de ensinar e aprender dentro do contexto social em que vivemos (MORIN; GADOUA; GERARD, 2007).

\section{Considerações finais}

Ao final desta pesquisa foi possível corroborar outros estudos - e a realização das atividades propostas permitiu aos participantes terem tido a experiência com o objeto estudado - e, ao mesmo tempo, proporcionar a reflexão quanto à necessidade do conhecimento para o planejamento das atividades. Para elaborar o roteiro e desenvolver o plano de aula foi necessário realizar uma série de atividades individuais e em grupo, além de pesquisas que auxiliaram na construção do saber pela prática vivenciada.

O maior desafio em fazer teatro com ciência é relacionar a realidade com a ficção. É importante destacar que para entender o contexto da peça não há necessidade de ser especialista no tema proposto, pois o roteiro, quando bem elaborado didaticamente, traz conceitos e explicações que expressam não só o que se pretende ensinar, mas como essa informação é transmitida durante a encenação e de que forma chegará aos expectores. O texto precisa levar o expectador a repensar de forma analítica em como ocorreram os eventos apresentados na peça, ampliando o pensamento crítico da plateia e que reflitam sobre os questionamentos apontados.

A linguagem da divulgação científica utilizada no teatro não traz apenas a possibilidade de ouvir sobre os feitos que marcaram um momento da história, mas de pensar e questionar de que forma realmente ocorreram. Assim, viver esse roteiro em tempo real permite ao aluno ter a experiência dessa construção, em que a ficção e a realidade se misturam e tornam o aprendizado lúdico e divertido. O teatro no 
ambiente escolar não tem a preocupação com o espetáculo em si, mas com o ensino e a aprendizagem dos participantes como uma forma de interação.

Os apontamentos deste estudo refletem os problemas encontrados em todo nosso país. As discussões nos mostram a necessidade em problematizar o ensino e as novas metodologias de aprendizagem, para que possam ser realmente adequadas à realidade de cada instituição.

Portanto, o objetivo desta pesquisa ao trabalhar o teatro no ambiente de ensino foi alcançado, uma vez que observamos que as atividades realizadas contribuíram para o processo de formação dos futuros professores.

Espera-se que, diante da relevância das análises aqui apresentadas, este estudo leve uma provocativa aos estudantes, professores e demais pesquisadores da área, a refletirem sobre o ensino que está sendo realizado nas escolas e a forma com que atuamos no desenvolvimento das práticas pedagógicas. Dessa forma, acreditamos que ações como esta possam propiciar a problematização acerca da importância do conhecimento científico na formação de professores, a partir de práticas que promovam a discussão e a apropriação dos conceitos científicos no ambiente escolar.

\section{Referências}

BARBOSA, G. A.; AIRES, J. A.; GONÇALVES, R. A linguagem na divulgação científica: uma analise da Revista Mundo Estranho. In: ENCONTRO NACIONAL DE ENSINO DE QUÍMICA, 16., 2012, Salvador. Anais [...]. Salvador: SBQ, 2012. p. 1-12. Disponível em: https://periodicos.ufba.br/index.php/ anaiseneq2012/article/view/7427. Acesso em: 17 out. 2021.

BARDIN, L. Análise de conteúdo. São Paulo: Edições 70, 2016.

BRASIL. Lei no 4.024, de 20 de dezembro de 1961. Fixa as diretrizes e bases da educação nacional. Brasília, DF: [Congresso Nacional, 1961]. Disponível em: https://cutt.ly/4RiOZ7W. Acesso em: 15 out. 2021.

CAMPANINI, B. D. Ciência em cena: uma proposta de sequência didática interativa sobre teatro científico na formação de professores. 2019. Tese (Doutorado em Ciência, Tecnologia e Educação) - Centro Federal de Educação Tecnológica Celso Suckow da Fonseca, Rio de Janeiro, 2019.

COELHO, M. A. Teatro na escola: uma possibilidade de educação efetiva. Revista Polêm!ca, Rio de Janeiro, v. 13, n. 2, p. 1-12, 2014. Disponível em: https://cutt.ly/ARfG2RV. Acesso em: 15 out. 2021.

CUNHA, R. B. Alfabetização científica ou letramento científico?: interesses envolvidos na interpretação do conceito de scientific literacy. Revista Brasileira de Educação, Rio de Janeiro, v. 22, n. 68, p. 169-186, 2017. DOI: https://doi.org/g23m.

FARIA, J. R. A história do teatro brasileiro: das origens ao teatro profissional da primeira metade do século XX. São Paulo: Perspectiva, SESC, 2012. v. 1.

FARIA, J. R. A história do teatro brasileiro: do modernismo às tendências contemporâneas. São Paulo: Perspectiva: SESC, 2013. v. 2.

GIL, A. C. Como elaborar projetos de pesquisa. 4. ed. São Paulo: Atlas, 2002.

ISZLAJI, C.; NOVO, J. Q.; MARTINS, L. C.; MARANDINO, M. Formando jovens divulgadores da ciência, ações de alfabetização e divulgação científica. Revista da SBEnBio, São Paulo, n. 7, p. 1431-1440, 2014.

MORIN, A.; GADOUA, G.; GERARD, P. Saber, ciência, ação. São Paulo: Cortez, 2007. 
MORTIMER, E. F. Uma agenda para a pesquisa em educação em ciências. Revista Brasileira de Pesquisa em Educação em Ciências, Belo Horizonte, v. 2, n. 1, p. 36-59, 2002. Disponível em: https://periodicos.ufmg.br/index.php/rbpec/article/view/4148. Acesso em: 15 out. 2021.

OLIVEIRA, M. M. D. Sequência didática interativa no processo de formação de professores. Petrópolis: Vozes, 2013.

OSBORNE, J. Science education for the twenty first century. Eurasia Journal of Mathematics, Science \& Technology Education, UK, v. 3, n. 3, p. 173-184, 2007. DOI: https://doi.org/gjrpv7.

PEREIRA, A. S.; SANTOS, P. M. Contribuições do teatro científico para a formação inicial docente em química. Perspectivas em Diálogo: revista de educação e sociedade, Brasil, v. 4, n. 7, p. 130149, 2017.

PIMENTA, S. G.; ANASTASIOU, L. G. C. Docência no ensino superior. 5. ed. São Paulo: Cortez, 2014.

ROCHA, M. B. O potencial didático dos textos de divulgação científica segundo os professores de ciências. Revista Brasileira de Ensino de Ciência e Tecnologia, Curitiba, v. 5, n. 2, p. 47-68, 2012. DOI: https://doi.org/g23p.

RODRIGUES, M. Arte e ciência para lidar com um mundo complexo. Ciência e Cultura, São Paulo, v. 70, n. 1, p. 60-61, 2018. DOI: https://doi.org/g23q.

SILVA, J. B.; ANDRADE, M. H.; OLIVEIRA, R. R.; SALES, G. L.; ALVES, F. R. V. Tecnologias digitais e metodologias ativas na escola: o contributo do Kahoot para gamificar a sala de aula. Revista Thema, Pelotas, RS, v. 15, n. 2, p. 780-791, 2018. DOI: https://doi.org/g23r.

SILVEIRA, A. F.; SILVA, A. P. B.; RIBEIRO FILHO, A. A divulgação da ciência através do teatro: um estudo em Copenhague de Michael Frayn. In: ENCONTRO NACIONAL DE PESQUISA EM EDUCAÇÃO EM CIÊNCIAS. 7., 2009, Florianópolis. Atas [...]. Rio de Janeiro: Abrapec, 2009. Disponível em: https://cutt.ly/iRfCpe7. Acesso em: 15 out. 2021.

SOUSA, J. G. D. O teatro no Brasil. Rio de Janeiro: Instituto Nacional do livro, 1960.

SOUZA, L. D.; CALDEIRA, A. G. D. S.; SOUZA JUNIOR, F. S.; FALCONIERI, A. G. F. Teatro científico e formação profissional de professores em química: a experiência do grupo FANÁTicos da química. In: ENCONTRO NACIONAL DE PESQUISA EM EDUCAÇÃO EM CIÊNCIAS, 10., 2015, Águas de Lindóia. Atas [...]. Rio de Janeiro: Abrapec, 2015. Disponível em: http://www.abrapecnet.org.br/ enpec/x-enpec/anais2015/busca.htm. Acesso em: 15 out. 2021.

TARDIF, M. Saberes docentes e formação profissional. 17. ed. Petrópolis: Vozes, 2014. 